\title{
Permafrost Investigations Below The Marine Limit At Nain, Nunatsiavut, Canada
}

\section{Robert G. Way, Ph.D., ${ }^{1}$ Antoni Lewkowicz, Ph.D., ${ }^{2}$ Yifeng Wang, M.Sc., ${ }^{3}$ Paul McCarney, Ph.D. ${ }^{4}$}

\footnotetext{
${ }^{1}$ Assistant Professor, Northern Environmental Geoscience Laboratory, Department of Geography and Planning, Queen's University (corresponding author). Email: robert.way @ queensu.ca ${ }^{2}$ Department of Geography, Environment and Geomatics, University of Ottawa. Email: alewkowi@uottawa.ca ${ }^{3}$ Northern Environmental Geoscience Laboratory, Department of Geography and Planning, Queen's University. Email: yifeng.wang @ queensu.ca ${ }^{4}$ Department of Lands and Natural Resources, Nunatsiavut Government. Email: pcm.mccarney@gmail.com
}

This manuscript has undergone peer-review and has been accepted for publication in the American Society of Civil Engineers Proceedings for the 2021 Regional Conference on Permafrost and the $19^{\text {th }}$ International Conference on Cold Regions Engineering. Please feel free to contact the corresponding author with any questions or feedback. 


\begin{abstract}
Discontinuous permafrost is a challenge for development in the coastal communities of Nunatsiavut, Labrador, northeast Canada, where local high relief limits suitable terrain for construction. These issues are particularly pronounced in Nain, the largest and northernmost community in Nunatsiavut, which is undergoing rapid population growth and expansion. In this study, DC electrical resistivity tomography was combined with geotechnical borehole records and in situ field data to evaluate the distribution of permafrost at four sites in the lowest parts of the community. Permafrost was identified in at least six of the seven geophysical transects, including beneath culturally critical community infrastructure. A supra-permafrost talik was imaged beneath a convenience store that has experienced extreme differential subsidence, demonstrating that excess ice exists in some of the region's frozen sediments. The presence of permafrost near the shoreline likely reflects ground cooling due to wind-scouring of snow at the exposed sites and the thermal impact of frost-susceptible sediments. Despite uncertainties in geophysical interpretation due to local site disturbance and coarse near-surface fill at some sites, these results have important implications for future development in this northern coastal community.
\end{abstract}




\section{INTRODUCTION}

Projected warming of northern Canada is expected to affect permafrost bodies throughout the sporadic discontinuous zone over the next century (Woo et al. 1992, Zhang et al. 2008). Baseline information on local permafrost distribution and characteristics, as well as careful planning and adaptation measures, are required to avoid structural damage to existing and future infrastructure in these regions (Nelson et al. 2001, Smith and Riseborough 2010, Hong et al. 2014). In eastern Canada, permafrost-focused studies have been undertaken throughout Nunavik, northern Québec (e.g., Beaulieu and Allard 2003, Payette et al. 2004, Fortier et al. 2008, Allard et al. 2012), but there is a paucity of comparable information for communities in Nunatsiavut, northern Labrador.

In this paper, we present geophysical and local site investigations in Nain $\left(56^{\circ} 32^{\prime} \mathrm{N}\right.$, $61^{\circ} 42^{\prime} \mathrm{W}$; Figure 1), which examine the contemporary distribution of permafrost in the community and its implications for local infrastructure. Nain, which developed around a Moravian mission established in 1771, is both the northernmost and largest community in Nunatsiavut. Due to rapid population growth, systematic overcrowding in housing, and degrading existing infrastructure, there is an urgent need for community expansion, including the construction of new housing and a new airstrip. Suitable construction sites around Nain are limited because of topographic relief, hydrological conduits, and frost-susceptible marine deposits (Bell et al. 2011).

Nain is located in the sporadic discontinuous permafrost zone and ice content is inferred to be low to medium (Heginbottom et al. 1995, Way and Lewkowicz 2016). The overall impact of climate-induced permafrost degradation is expected to be medium, due to a projected low physical and moderate thermal response of soil to warming, but there is considerable uncertainty at finer spatial scales (Smith and Burgess 2004). Permafrost has been identified as a contributing factor to ground subsidence and structural damage to some buildings in the community (Bell et al. 2011, Smith and Melendy 2015, Way and Lewkowicz 2015), but permafrost distribution and conditions in the region have not been described in detail in recent academic literature.

\section{STUDY AREA}

Nain has a Subarctic climate with a mean annual air temperature of $-2.5^{\circ} \mathrm{C}(1981-2010)$ and cool summers $\left(\sim 9.2^{\circ} \mathrm{C}\right.$; Environment Canada 2020). Regional mean annual air temperatures have increased by $\sim 1.5^{\circ} \mathrm{C}$ since the early 20 th Century, and significant warming has occurred in the region from 1987 to 2016 in both winter and summer, albeit with greater winter variability (Barrette et al. 2020). Mean cold-season snow thickness at Nain averages $67 \mathrm{~cm}$ (1981-2010; Environment Canada 2020), but a decrease in snow cover duration and a reduced fraction of solid precipitation have been observed in Nunatsiavut between 1980 and 2014 (Barrette et al. 2020).

Nain is situated in a WSW to ENE trending U-shaped valley, bordered to the north and south by high ridges and plateaux (200-250 m a.s.l.) of igneous bedrock of Proterozoic age (Wardle et al. 1997). Reworked tills are widespread in the community (Occhietti et al. 2011), while glaciofluvial sands and gravels are common in the valley floor, as are alluvial deposits (Bell et al. 
2011). The marine limit at Nain is approximately $40 \mathrm{~m}$ a.s.l. (Vacchi et al. 2018), but Holocene marine sediments consisting of sands and muds have been observed only to elevations of $\sim 20 \mathrm{~m}$ a.s.1. (Bell et al. 2011).

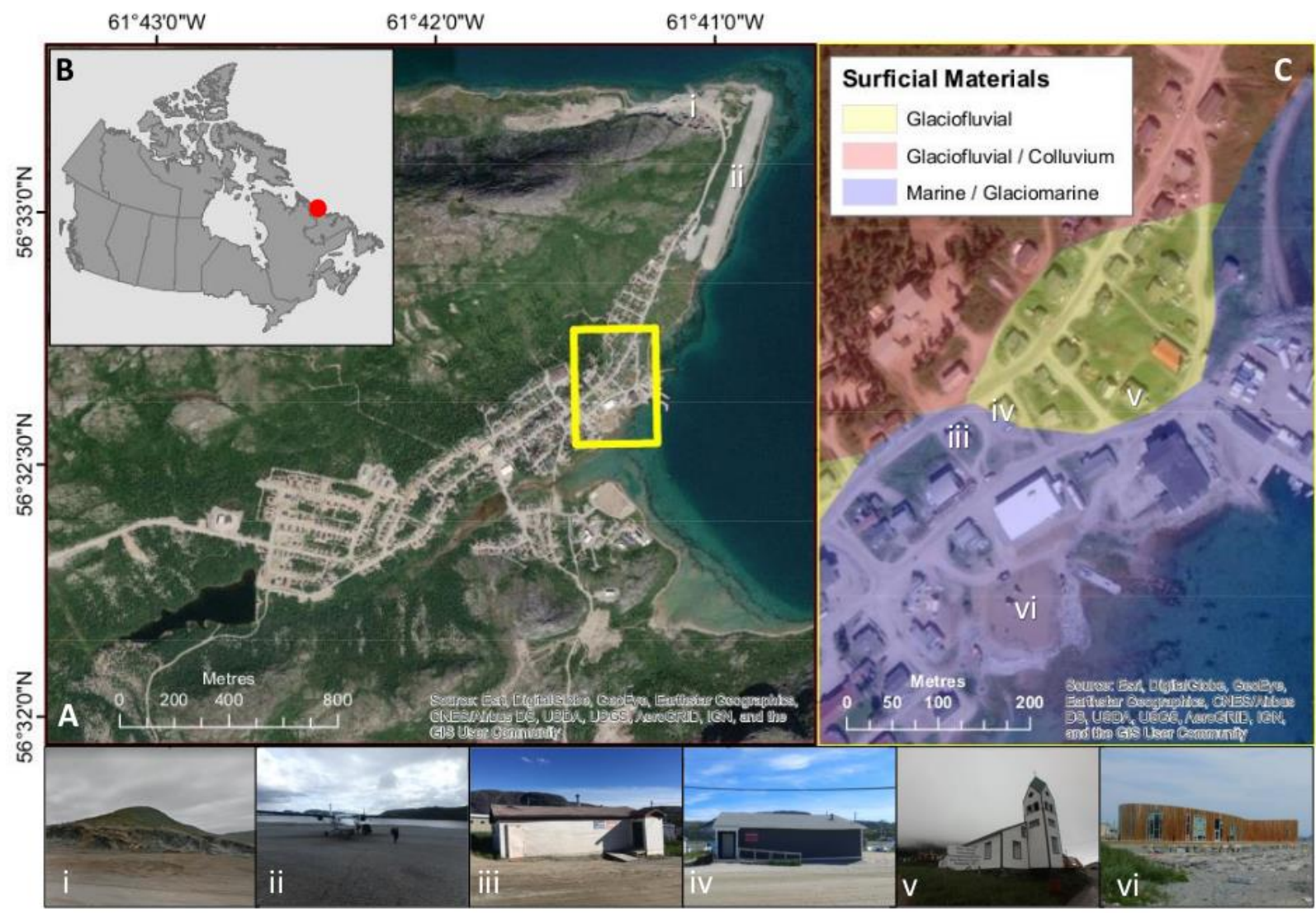

Figure 1. A) Satellite image of Nain showing the location of (i) a rock excavation site near the community dump (Google Maps) and (ii) the community airstrip; B) Inset map situating Nain relative to Canada; $C$ ) Distribution of surficial materials in the centre of the community (Bell et al. 2011) showing the location of (iii) the Puffin Snacks convenience store, (iv) the post office, (v) the Moravian Church, and (vi) the Illusuak Cultural Centre.

\section{METHODOLOGY}

Field investigations. Permafrost conditions were investigated using DC electrical resistivity tomography (ERT), frost probing, and instantaneous ground temperature measurements along seven transects below the marine limit in late-July of 2014 and 2018. Vegetation and surficial materials were also recorded. An ABEM Terrameter LS was used with electrodes in a Wenner array ( 1 or $2 \mathrm{~m}$ spacing) on profiles 40 to $200 \mathrm{~m}$ long (Table 1). Apparent resistivities were inverted with RES2DINV (Loke et al. 2003) using the robust inversion method until the modelled pseudosection's errors declined by less than 1\% between iterations (maximum of five iterations; Way et al. 2018, Davis et al. 2020). Inverted resistivities were exported as x-y-z values, and model 
blocks were plotted in R v3.6. Transects were topographically corrected prior to inversion with surface slope measurements collected with a Brunton compass or a clinometer, while starting elevations were determined with a hand-held GPS ( $\pm 5 \mathrm{~m}$; Lewkowicz et al. 2011).

Frost tables were measured along three ERT profiles using a $120 \mathrm{~cm}$-long probe and were validated at selected locations with instantaneous ground temperature measurements collected with Onset Hobo UX120-006M 4-Channel Analog Data Loggers $\left( \pm 0.15^{\circ} \mathrm{C}\right.$; Way and Lewkowicz 2015, Davis et al. 2020, Holloway and Lewkowicz 2020). Ground temperatures were recorded at the base of the probed hole for 10 to 15 minutes to allow for thermal equilibration.

Table 1. Summary of ERT surveys performed in Nain in 2014 and 2018.

\begin{tabular}{lcccccc}
\hline ID & Site & $\begin{array}{c}\text { Elevation } \\
\text { (m a.s.1.) }\end{array}$ & $\begin{array}{c}\text { Length } \\
(\mathrm{m})\end{array}$ & $\begin{array}{c}\text { Minimum } \\
\text { Spacing (m) }\end{array}$ & $\begin{array}{c}\text { Depth of } \\
\text { Investigation (m) }\end{array}$ & Survey Date \\
\hline S1 & Illusuak Cultural Centre (across) & 6 to 4 & 200 & 2 & 26 & $2014-07-20$ \\
S2 & Illusuak Cultural Centre (sloping) & 9 to 3 & 120 & 2 & 23 & $2014-07-20$ \\
S3 & Northern Shoreline (across) & 11 to 7 & 80 & 1 & 15 & $2018-07-26$ \\
S4 & Northern Shoreline (sloping) & 12 to 6 & 106 & 1 & 20 & $2018-07-26$ \\
S5 & Puffin Snacks (short) & 7 to 4 & 40 & 1 & 7.5 & $2014-07-19$ \\
S6 & Puffin Snacks (long) & 8 to 7 & 80 & 2 & 15 & $2014-07-19$ \\
S7 & Southern Shoreline & 1 to 6 & 80 & 1 & 15 & $2014-07-20$ \\
\hline
\end{tabular}

The probability of frozen ground in marine sediments along ERT transects was estimated with a statistical model developed from modelled resistivities and co-located frost table observations (e.g., Way et al. 2018). ERT model block resistivities, averaged from 0.50 to $1.05 \mathrm{~m}$ below the ground surface, were compared to co-located observations of frozen ground presence or absence determined by frost probing (Figure 2A). A maximum likelihood logistic regression model ( $\mathrm{p}<0.01$; AIC=37) was used to relate the near-surface model block resistivities to permafrost presence or absence for derivation of frozen ground probabilities in marine sediments in Nain (Figure 2B). This method offered a quantitative means of estimating permafrost distribution and was used to inform qualitative interpretations of ERT profiles. 


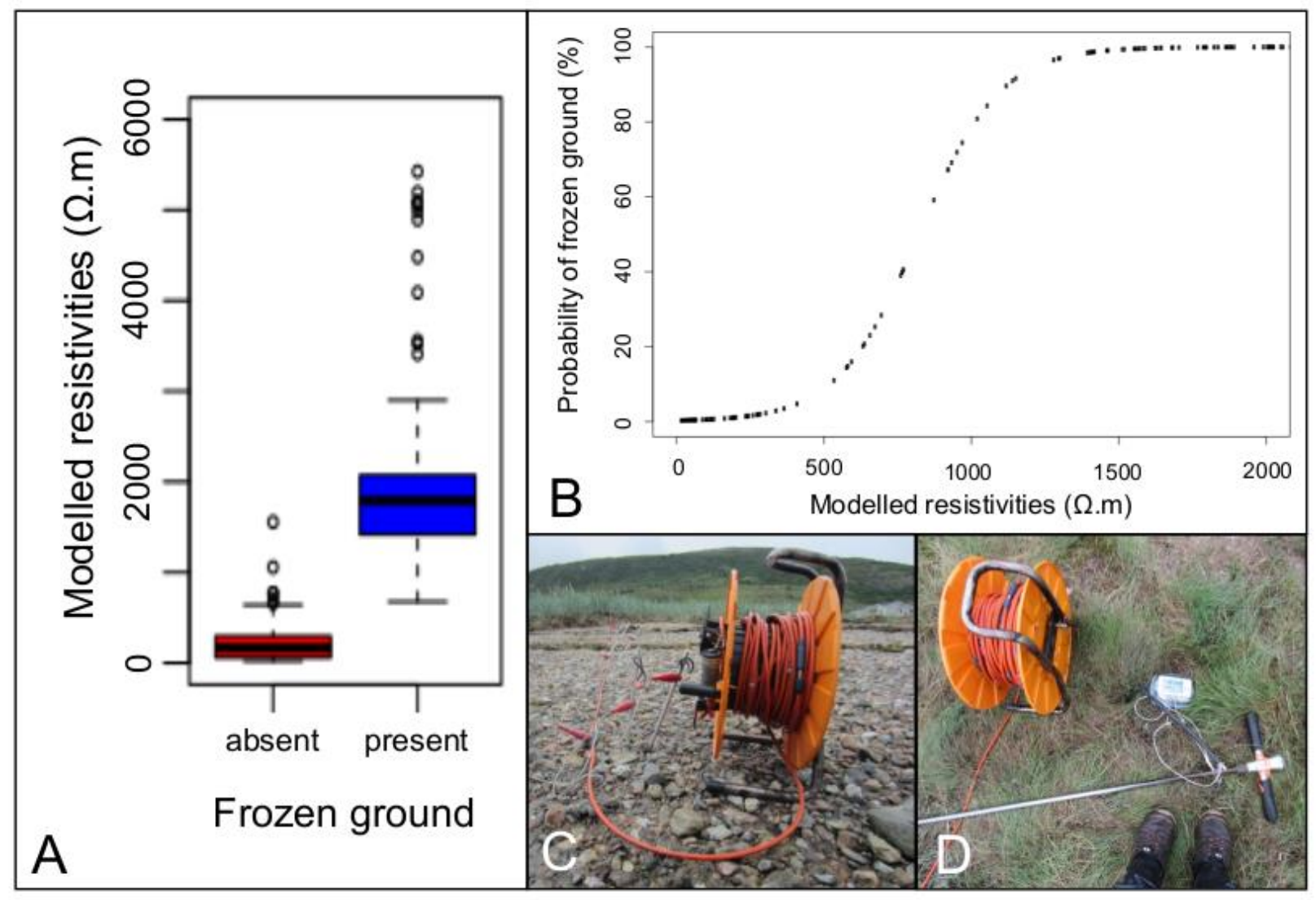

Figure 2. A) Near-surface modelled resistivities at surveys S1, S3, and S4 grouped by absence or presence of frozen ground (see Table 1); B) Frozen ground probabilities estimated using a logistic regression of near-surface frozen ground absence or presence as a function of modelled resistivities for surveys S1, S3, and S4; C) End of ERT survey S4; D) ERT equipment, frost probe, and instantaneous temperature logger.

Ancillary Data. The Nunatsiavut Government made available geotechnical borehole logs collected at 80 locations throughout the community by Stantec Consulting Ltd. (Stantec 2012; n=9) and Exp Services Inc. (Smith and Melendy 2015; n=71). The Stantec boreholes were drilled during construction of the Illusuak Cultural Centre (Figure 1) in 2012 and described surficial materials to depths of up to $23.5 \mathrm{~m}$. The Exp boreholes were drilled at selected locations within the community in 2014 and characterized surficial materials to depths of up to $10 \mathrm{~m}$.

\section{RESULTS}

The seven ERT surveys were completed at four locations (Table 1; Figure 3). Depth of investigation ranged from 7.5 to $26 \mathrm{~m}$ (Table 1). 


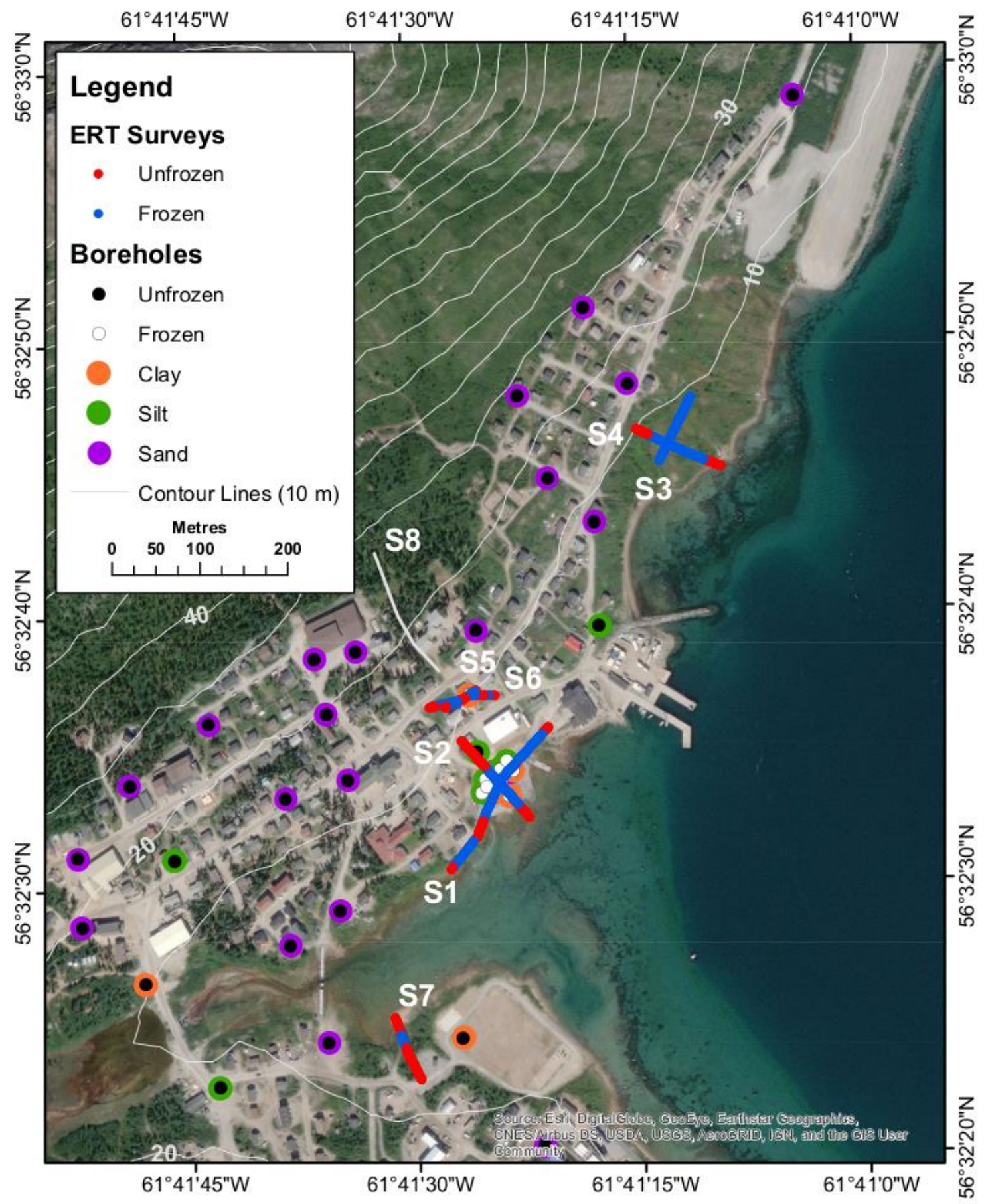

Figure 3. ERT transects and boreholes completed in central Nain. Sections of ERT surveys inferred to be frozen (blue) or unfrozen (red) are shown for the Illusuak Cultural Centre S1) across and S2) sloping; Northern Shoreline S3) across and S4) sloping; Puffin Snacks S5) short and S6) long; and S7) Southern Shoreline surveys. S8 shows an ERT survey completed by Way and Lewkowicz (2015). Boreholes (Stantec 2012, Smith and Melendy 2015) are classified by presence of frozen or unfrozen sediments and the finest sediment layer present. 
According to the probabilistic relationship shown in Figure 2B, frozen ground was present at all four sites investigated and in all seven profiles, with a minimum thickness of $0.5 \mathrm{~m}$ and a maximum thickness of greater than $20 \mathrm{~m}$ (Figure 4).
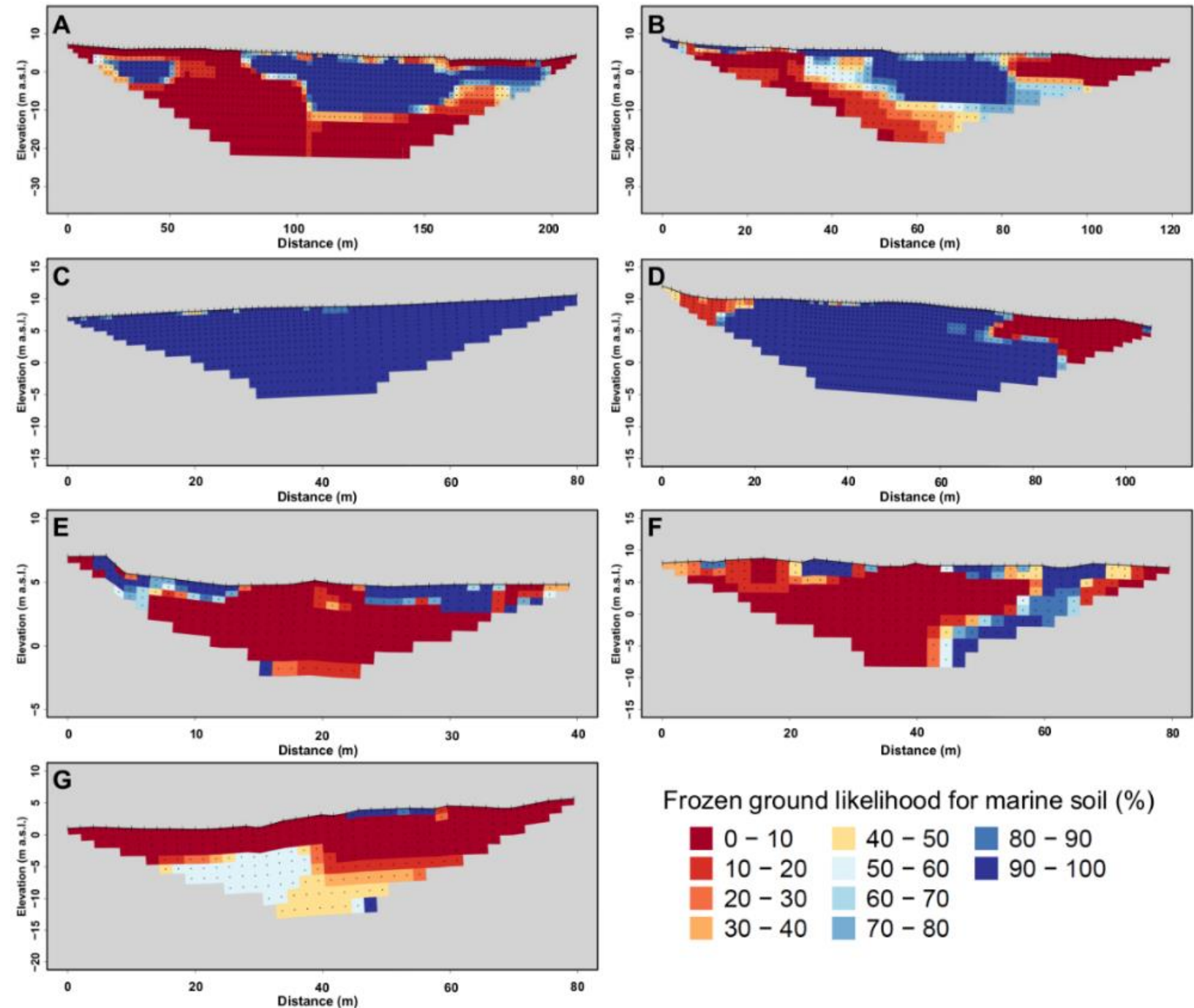

Frozen ground likelihood for marine soil (\%)

$\begin{array}{lll}0-10 & 40-50 & 80-90 \\ 10-20 & 50-60 & 90-100 \\ 20-30 & 60-70 & \\ 30-40 & 70-80 & \end{array}$

Figure 4. Frozen ground probabilities for marine sediments for the Illusuak Cultural Centre A) across and B) sloping; Northern Shoreline C) across and D) sloping; Puffin Snacks E) short and F) long; and G) Southern Shoreline ERT surveys. Frozen ground likelihood was estimated with binomial logistic regression using measured resistivities and thaw depths.

Illusuak Cultural Centre. ERT surveys S1 and S2 were performed across poorly drained medium to coarse sediments along the partially vegetated (grasses and sedges) shoreline zone and across a gravel pad prepared for the construction of the Illusuak Cultural Centre. Survey S1 ran parallel to the shoreline, traversing the gravel pad from 98 to $152 \mathrm{~m}$ along the profile (Figure 4A). Frozen ground probabilities were low in the first $70 \mathrm{~m}$ of the survey, except for a small body with higher resistivities at depths of 3 to $9 \mathrm{~m}$ near the start of the transect. This was interpreted as being a body 
of warm permafrost with a thick active layer $(>120 \mathrm{~cm})$ or possibly a supra-permafrost talik. Permafrost was inferred to occur from the surface or near-surface to a depth of $6 \mathrm{~m}$ between 68 and $92 \mathrm{~m}$ along the survey, from the surface or near-surface to a depth of $18 \mathrm{~m}$ between 92 and $152 \mathrm{~m}$ near the centre of the survey, and from depths of 2 to $8 \mathrm{~m}$ between 152 and $190 \mathrm{~m}$ near the end of the survey. Survey S2 ran perpendicular to the shoreline, beginning in a gravel lot near the community fire hall and traversing the Illusuak Cultural Centre construction site from 58 to $92 \mathrm{~m}$ along the survey before ending in the tidal zone (Figure 4B). Frozen ground probabilities were high in the upper 1 to $2 \mathrm{~m}$ but were low at depth from 0 to $35 \mathrm{~m}$ along the survey, likely reflecting high resistivities within coarse fill in the near-surface, overlying unfrozen sediments at depth. Frozen ground was inferred to occur at $35 \mathrm{~m}$ along the survey and extended from the surface to the base of the profile, except for a body of unfrozen materials extending from the surface or nearsurface to depths of $6 \mathrm{~m}$ beginning at $40 \mathrm{~m}$ along the survey.

Drill logs from three boreholes near $\sim 102, \sim 119$, and $\sim 135 \mathrm{~m}$ along survey S1 and near $~ 86$ $\mathrm{m}$ along survey $\mathrm{S} 2$ show frozen sediments to a maximum depth of $22 \mathrm{~m}$ in August 2012 (Figure 3). An additional borehole drilled in November 2014 at $23 \mathrm{~m}$ along survey $\mathrm{S} 2$ confirmed the absence of frozen ground in this section of the survey (Figure 3). These results are consistent with the inferred depth and distribution of permafrost from the ERT surveys performed in July 2014.

Northern Shoreline. Surveys S3 and S4 were located near the shoreline about $250 \mathrm{~m}$ from the end of the airstrip. The ground surface was covered by sedges, grasses, and low shrubs, with several tall patches of willows (Salix spp.) measuring up to $2 \mathrm{~m}$. Survey S3 (Figure 4C) ran parallel to the shoreline through two distinct patches of willows. Frozen ground apparently extended from the surface to the base of the profile along the entire survey, although a short section from 19 to $22 \mathrm{~m}$ along the transect was inferred to exhibit $\sim 1 \mathrm{~m}$ of thaw from the surface. The latter corresponded to the centre of a $20 \mathrm{~m}$-long patch of willows, measuring about $1 \mathrm{~m}$ high. Survey S4 ran perpendicular to the shoreline, starting in a tall willow patch $(>1.5 \mathrm{~m})$, running through alternating sections of grass and shrubs, before ending on unvegetated beach sands and gravels (Figure 4D). Frozen ground probabilities were highest in the middle of the survey, while ground was inferred to be unfrozen at the start of the survey, beneath tall willows and wet grasses, and at the end of the survey, on the grassy to unvegetated beach. Frozen ground likely extended from the near-surface to the base of investigation between 16 and $84 \mathrm{~m}$ along the survey, although deeper thaw was inferred past $71 \mathrm{~m}$ along the survey. The latter could represent the presence of a talik or may be due to saltwater incursion from the adjacent inlet. A $1 \mathrm{~m}$-thick thawed section between 36 and $42 \mathrm{~m}$ along the profile corresponded to the edge of a patch of willows $(\sim 1 \mathrm{~m})$ and a winter snowmobile trail. Resistivities at the Northern Shoreline site were higher than those observed at the nearby Illusuak Cultural Centre site, suggesting greater frozen moisture contents. A number of possibilities could account for this difference, including colder ground temperatures, lower salinities, higher ground ice contents, and coarser sediments. The two boreholes nearest to the ERT profiles were both in sands (Figure 3) and were unfrozen to completion depths of $4.9 \mathrm{~m}$. 
Puffin Snacks. Surveys S5 and S6 were conducted across an open yard and two gravel paths adjacent to the Puffin Snacks convenience store. The building exhibited a $\sim 5^{\circ}$ longitudinal tilt due to differential settlement, hypothesized to be due to permafrost thaw. The two surveys shared a mid-point, and the side of the building was located between 7.5 and $19.5 \mathrm{~m}$ in survey S5 and 27.5 and $39.5 \mathrm{~m}$ in survey S6 (Figure 4E-F). High modelled probabilities of frozen ground were evident in the upper 2 metres along parts of both surveys, including below the side of the building. However, these are likely due to deep seasonal frost and/or coarse unfrozen fill because frozen ground probabilities were much lower below a depth of 2 metres. In the longer and deeper survey S6, frozen material was interpreted at depths of 11 to $15 \mathrm{~m}$ at $45 \mathrm{~m}$ along the survey and from the surface to the base of the profile from 60 to $65 \mathrm{~m}$ along the survey. Thus, permafrost was inferred to exist to the base of the profile $(>15 \mathrm{~m}$ ) between 45 and $65 \mathrm{~m}$, beneath a supra-permafrost talik up to $8 \mathrm{~m}$ thick.

A borehole drilled to a depth of $10.1 \mathrm{~m}$ in November 2014 about $3 \mathrm{~m}$ downslope of the overlapping section of surveys S5 and S6, at $\sim 14 \mathrm{~m}$ along survey S5 and $\sim 34 \mathrm{~m}$ along survey S6 (Figure 3), found a $3 \mathrm{~m}$-thick body of frozen ground beneath a $3.5 \mathrm{~m}$-thick unfrozen layer. Temperatures at depth, measured in November 2014 , were just below $0^{\circ} \mathrm{C}$. This borehole shows the presence of degrading thin permafrost, while the results from surveys S5 and S6 indicate an absence of frozen ground immediately next to the building in the same year.

Southern Shoreline. Survey S7 was performed across a range of surface and vegetation conditions adjacent to a playground on the community's southern shoreline (Figure 4G). The transect started in unvegetated sandy foreshore that transitioned upslope to grasses and sedges, then dwarf birch (Betula glandulosa) and willow shrubs, to a patch of open forest composed of balsam fir (Abies balsamea) and tamarack (Larix laricina), before ending on a gravel pad. Frozen ground was inferred to occur at this site to a maximum depth of 0.5 to $1.5 \mathrm{~m}$ beneath a section of low shrubs $(<40 \mathrm{~cm})$ between 44 and $58 \mathrm{~m}$ along the survey. Frost probing and instantaneous temperature measurements confirmed the presence of frozen ground at these depths, but probing resulted in penetration through the frozen layer at some locations, suggesting that the thin body of frozen ground at this site was late-lying seasonal frost rather than permafrost. The two closest boreholes showed unfrozen sediments to completion depths of up to $9.15 \mathrm{~m}$. Consequently, the moderate resistivities and medium frozen ground probabilities at depths exceeding 5 to $7 \mathrm{~m}$ are probably not bedrock and are tentatively interpreted as degrading permafrost.

\section{DISCUSSION}

Permafrost Distribution in Marine Sediments in Nain. The borehole logs suggest that permafrost is not widespread in Nain. Unfrozen ground underlies much of the community where sand is usually the finest dominant sediment type (Stantec 2012, Smith and Melendy 2015; Figure 3). Only the boreholes drilled at the Illusuak Cultural Centre construction site and near the Puffin Snacks convenience store intersected frozen ground. However, permafrost presence has been 
reported elsewhere in low-lying marine deposits within the community. For example, construction workers observed ice-rich frozen ground at depths of 3 to $4 \mathrm{~m}$ in a $25 \mathrm{~m}$-long section along a water and sewage line ditch near the community's southern shoreline and to a depth of at least $12 \mathrm{~m}$ during drilling and blasting of rock near the community dump (Jamie Ryan, Budgell's Equipment and Rental Ltd., personal communication, January 26, 2021; Figure 1).

The development of permafrost and its contemporary state adjacent to the shoreline is likely due to lower ground temperatures caused by extensive wind scouring and densification of snow in the open area near the shoreline and by the thermal impact of frost-susceptible soils. Permafrost is present in similar low-lying locales within fine-grained marine sediments in Nunavik (Fortier et al. 2008), including along the coast of Hudson's Bay (Beaulieu and Allard 2003). There are several indications that permafrost distribution has been impacted by the built environment in the community. Part of the Illusuak Cultural Centre site was occupied by a caribou processing plant constructed in 1988 that suffered severe subsidence and was demolished after only 5 years (Meis Mason et al. 2007). The Puffin Snacks store, which is still in use despite its tilt, has obviously been affected by localized ground warming. Ground subsidence has occurred along the community airstrip (Mitchell 2018), and the current Moravian Church, constructed in 1923, has had to be jacked up by at least $0.75 \mathrm{~m}$ to level it (Smith and Melendy 2015).

This local knowledge, combined with recent geophysical and geotechnical investigations, including in nearby forested upland locations (Survey S8 in Figure 3; Way and Lewkowicz 2015), suggests that the combined effects of more than two centuries of permanent structures and widespread surface disturbance, including the clearing of vegetation for built infrastructure, may have degraded formerly present permafrost bodies throughout the community, leaving mostly residual patches near the shoreline. This interpretation is supported by modelling studies by Zhang et al. (2006) and Way and Lewkowicz (2016), which suggest that areas around Nain have experienced widespread permafrost degradation in response to regional warming over the past century. Due to the variable ground thermal and hydrological conditions within the community, the establishment of a permafrost thermal monitoring program would improve our understanding of regional permafrost susceptibility to future climate change (e.g., Smith et al. 2005).

Challenges of Detecting Permafrost in Coastal Labrador. Interpretation of permafrost conditions in Nain was challenging for several reasons. First, additional validation sources were required to inform interpretations of the ERT surveys. The probabilistic statistical model that was developed from modelled resistivities and frost table observations offered a quantitative means of interpreting otherwise qualitative results, but it relied on the assumption of a homogeneous substrate within each profile and between all profiles, which may not be the case. Second, the interpretation of frozen versus unfrozen ground was further complicated by the presence of coarse surficial materials in some surveys, including coarse fill and/or gravel roads or surfaces at the Illusuak Cultural Centre, Puffin Snacks, and Southern Shoreline sites. Unfrozen dry coarse materials exhibit resistivities that can overlap with those obtained in frozen ground. Third, coastal Labrador is characterized by cool summers (Maxwell 1981, Way et al. 2018), which may preserve 
seasonal frost long into the summer, such as at the Puffin Snacks and Southern Shoreline sites. Discrimination between seasonally and perennially frozen ground in Nain was not always possible using techniques such as frost probing and instantaneous ground temperature measurements. Fourth, ERT profiles and field data indicated the presence of deep active layers $(>120 \mathrm{~cm})$ or supra-permafrost taliks at the Illusuak Cultural Centre and Puffin Snacks sites. Without long-term temperature monitoring at depth, it is not possible to conclusively differentiate between the active layer and a talik, thus complicating our understanding of permafrost stability.

\section{CONCLUSION}

In this study, ERT surveys, field observations, geotechnical reports, and local knowledge were combined to characterize permafrost bodies within low-lying marine deposits in Nain. Permafrost was present to depths of at least $20 \mathrm{~m}$ at two sites, has partially degraded at a third site, and may be absent or present only beneath a talik at a fourth. The state and persistence of permafrost along the Nain shoreline is attributed to local factors, including frost-susceptible soils and thin layers of high-density snow in response to the low vegetation and the wind-exposed locale. The presence of deep active layers, supra-permafrost taliks, and buildings experiencing differential settlement demonstrates permafrost degradation beneath built infrastructure, indicating that permafrost extent may have been greater in the past. The findings underline that permafrost must be considered during community expansion and site-selection initiatives in Nain, particularly at sites adjacent to the shoreline. Long-term ground thermal monitoring would be an effective means of improving our characterization of regional permafrost risks and hazards.

\section{ACKNOWLEDGEMENTS}

We acknowledge that this research was undertaken on the traditional lands of the Labrador Inuit with the permission of the Nunatsiavut Government. We thank the Nunatsiavut Research Centre, the Nunatsiavut Government, and the Labrador Institute for their logistical and in-kind support, and we gratefully acknowledge Tom Sheldon, Christina Goldhar, Carla Pamak, Kristeen McTavish, and Rodd Laing for their collaboration and support of this work. We are grateful to Jason Smith of Exp Services Inc. and Jamie Ryan of Budgell's Equipment and Rental Ltd. for their insightful discussions and to Alex Brooker, Frédéric Dwyer-Samuel, and Caitlin Lapalme for their field or logistical assistance in 2014 and/or 2018. Financial support for this research was provided

by the University of Ottawa, Queen's University, Polar Knowledge Canada, and the W. Garfield Weston Foundation. 


\section{REFERENCES}

Allard, M., Lemay, M., Barrette, C., L’Hérault, E., Sarrazin, D., Bell, T., Doré, G. (2012). "Permafrost and Climate Change in Nunavik and Nunatsiavut: Importance for Municipal and Transportation Infrastructures." In Nunavik and Nunatsiavut: From Science to Policy. An Integrated Regional Impact Study (IRIS) of Climate Change and Modernization.

Barrette C., Brown R., Way R., Mailhot A., Diaconescu E.P., Grenier P., Chaumont D., Dumont D., Sévigny C., Howell S., Senneville S. (2020). "Nunavik and Nunatsiavut Regional Climate Information Update." In Nunavik and Nunatsiavut: From Science to Policy. An Integrated Regional Impact Study (IRIS) of Climate Change and Modernization, Second Iteration.

Beaulieu, N., and Allard, M. (2003). "The Impact of Climate Change on an Emerging Coastline Affected by Discontinuous Permafrost: Manitounuk Strait, Northern Quebec." Can. J. Earth Sci., 40(10), 1393-1404.

Bell, T., Putt, M., Sheldon, T. (2011). "Landscape Hazard Assessment in Nain: Phase I: Inventory of Surficial Sediment Types and Infrastructure Damage." Final Report to Nunatsiavut Government and Nain Inuit Community Government.

Davis, E., Trant, A., Hermanutz, L., Way, R.G., Lewkowicz, A.G., Siegwart Collier, L., Cuerrier, A., Whitaker, D. (2020). "Plant-Environment Interactions in the Low Arctic Torngat Mountains of Labrador.” Ecosystems, DOI: 10.1007/s10021-020-00577-6.

Environment and Climate Change Canada. (2020). "Canadian Climate Normal, 1981-2010." Historical Climate Data, www.climate.weather.gc.ca.

Fortier, R., Allard, M., Buteau, S., Calmels, F. (2008). "Internal Structure and Conditions of Permafrost Mounds at Umiujaq in Nunavik, Canada, Inferred from Field Investigation and Electrical Resistivity Tomography." Can. J. Earth Sci., 45(3), 367-387.

Heginbottom, J.A., Dubreuil, M.A., Harker, P.A. (1995). Canada Permafrost. National Atlas of Canada, $5^{\text {th }}$ edition, Natural Resources Canada.

Holloway, J.E. and Lewkowicz, A.G. (2020). "Half A Century of Discontinuous Permafrost Persistence and Degradation in Western Canada." Permafr. Periglac. Process., 31(1): 8596.

Hong, E., Perkins, R., and Trainor, S. (2014). "Thaw Settlement Hazard of Permafrost Related to Climate Warming in Alaska." Arctic, 67(1), 93-103.

Lewkowicz, A.G., Etzelmüller, B., and Smith, S.L. (2011). "Characteristics of Discontinuous Permafrost Based on Ground Temperature Measurements and Electrical Resistivity Tomography, Southern Yukon, Canada." Permafr. Periglac. Process., 22(4), 320-342.

Loke, M.H., Acworth, I., and Dahlin, T. (2003). "A Comparison of Smooth and Blocky Inversion Methods in 2D Electrical Imaging Surveys." Explor. Geophys., 34(3), 182-187.

Maxwell, J.B. (1981). "Climatic Regions of the Canadian Arctic Islands." Arctic, 34(3), 225-240. 
Meis Mason, A., Dana, L.-P., and Anderson, R. (2007). The Inuit Commercial Caribou Harvest and Related Agri-Food Industries in Nunavut." Int. J. Entrepreneurship and Small Business, 4(6), 785-806.

Mitchell, K. (2018, November 5). "Standing Committee on Indigenous and Northern Affairs." Canada. Parliament. House of Commons. 42nd Parliament, 1st Session, Meeting no. 127.

Nelson, F.E., Anisimov, O.A., and Shiklomanov, N.I. (2001). "Subsidence Risk from Thawing Permafrost." Nature, 410(6831), 889-890.

Occhietti, S., Parent, M., Lajeunesse, P., Robert, F., Govare, E. (2011). "Late Pleistocene-Early Holocene Decay of the Laurentide Ice Sheet in Québec-Labrador." Developments in Quaternary Sciences, 11, 601-630.

Payette, S., Delwaide, A., Caccianiga, M., Beauchemin, M. (2004). "Accelerated Thawing of Subarctic Peatland Permafrost Over the Last 50 Years." Geophys. Res. Lett., 31(18).

Smith, S.L., and Burgess, M.M. (2004). "Sensitivity of Permafrost to Climate Warming in Canada.” Bulletin 579, Geological Survey of Canada, DOI: 10.4095/216137.

Smith, J.A. and Melendy, W.G. (2015). “Community Wide Hazard Assessment, Nain, NL.” Final Report to Nunatsiavut Government.

Smith, S.L., and Riseborough, D.W. (2010). "Modelling the Thermal Response of Permafrost Terrain to Right-of-Way Disturbance and Climate Warming." Cold Reg. Sci. Technol., 60(1), 92-103.

Smith, S.L., Burgess, M.M., Riseborough, D., Nixon, F.M. (2005). "Recent Trends from Canadian Permafrost Thermal Monitoring Network Sites." Permafr. Periglac. Process., 16, 19-30.

Stantec Consulting Ltd. (2012). "Geotechnical Investigation Torngasok Cultural Centre Nain, NL." Final Report to Nunatsiavut Group of Companies.

Vacchi, M., Engelhart, S.E., Nikitina, D., Ashe, E.L., Peltier, W.R., Roy, K., Kopp, R.E., Horton, B.P. (2018). "Postglacial Relative Sea-Level Histories Along the Eastern Canadian Coastline." Quat. Sci. Rev., 201, 124-146.

Wardle, R.J., Gower, C.F., Ryan, B., Nunn, G., James, D.T., Kerr, A. (1997). Geological Map of Labrador. Geological Survey Map No. 97-07, Department of Mines and Energy, Government of Newfoundland and Labrador.

Way, R.G. and Lewkowicz, A.G. (2015). "Investigations of Discontinuous Permafrost in Coastal Labrador with DC Electrical Resistivity Tomography.” Proceedings of GeoQuébec 2015, 68 $8_{\text {th }}$ Canadian Geotechnical Conference and $7_{\text {th }}$ Canadian Permafrost Conference.

Way, R.G. and Lewkowicz, A.G. (2016). "Modelling the Spatial Distribution of Permafrost in Labrador-Ungava Using the Temperature at the Top of Permafrost." Can. J. Earth Sci., 53, 1010-1028.

Way, R.G., Lewkowicz, A.G., and Zhang, Y. (2018). "Characteristics and Fate of Isolated Permafrost Patches in Coastal Labrador, Canada." Cryosphere, 12, 2667-2688.

Woo, M., Lewkowicz, A.G., and Rouse, W.R. (1992). "Response of the Canadian Permafrost Environment to Climatic Change.” Phys. Geogr., 13(4), 287-317. 
Zhang, Y., Chen, W., and Riseborough, D.W. (2006). "Temporal and Spatial Changes of Permafrost in Canada Since the End of the Little Ice Age." J. Geophys. Res., 111, D22.

Zhang, Y., Chen, W., and Riseborough, D.W. (2008). "Transient Projections of Permafrost Distribution in Canada During the 21st Century Under Scenarios of Climate Change." Glob. Planet. Change, 60, 443-456. 